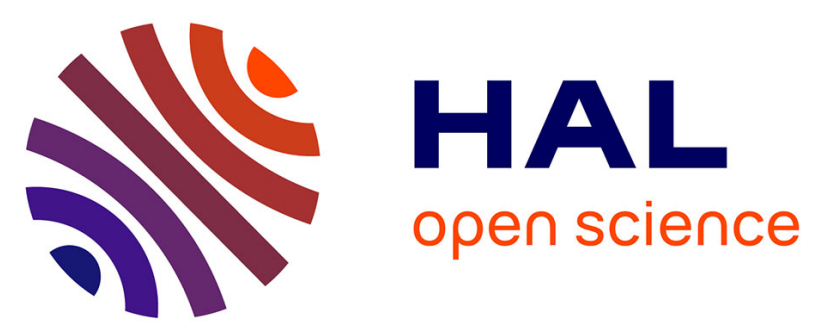

\title{
Psychological causes of noncompliance with electronically monitored occlusion therapy for amblyopia
}

Sjoukje Loudon, Jan Passchier, Layal Chaker, Sander de Vos, Maria Fronius, Richard Harrad, Caspar Looman, Brigitte Simonsz-Toth, Huibert Simonsz

\section{- To cite this version:}

Sjoukje Loudon, Jan Passchier, Layal Chaker, Sander de Vos, Maria Fronius, et al.. Psychological causes of noncompliance with electronically monitored occlusion therapy for amblyopia. British Journal of Ophthalmology, 2009, 93 (11), pp.1499-n/a. 10.1136/bjo.2008.149815 . hal-00477824

\section{HAL Id: hal-00477824 \\ https://hal.science/hal-00477824}

Submitted on 30 Apr 2010

HAL is a multi-disciplinary open access archive for the deposit and dissemination of scientific research documents, whether they are published or not. The documents may come from teaching and research institutions in France or abroad, or from public or private research centers.
L'archive ouverte pluridisciplinaire HAL, est destinée au dépôt et à la diffusion de documents scientifiques de niveau recherche, publiés ou non, émanant des établissements d'enseignement et de recherche français ou étrangers, des laboratoires publics ou privés. 
$1 \quad$ Psychological causes of noncompliance with electronically monitored

2 occlusion therapy for amblyopia

3

4 S E Loudon, J Passchier, L Chaker, S de Vos, M Fronius, R A Harrad, C W N Looman,

5 B Simonsz, H J Simonsz

6

7 Authors' affiliations:

8 S E Loudon, L Chaker, S de Vos, B Simonsz, H J Simonsz, Department of Ophthalmology, Erasmus

9 MC, University Medical Center Rotterdam, Rotterdam, the Netherlands

10 J Passchier, Department of Medical Psychology, Erasmus MC, University Medical Center Rotterdam,

11 Rotterdam, the Netherlands

12 M Fronius, Department of Ophthalmology, J.W.Goethe University, Frankfurt am Main, Germany

13 R A Harrad, Bristol Eye Hospital, Bristol, United Kingdom;

14 C W N Looman, B Simonsz, Department of Public Health, Erasmus MC, University Medical Center

15 Rotterdam, Rotterdam, the Netherlands

18 Trial Registration: clinicaltrials.gov Identifier: NCT 00131729

19 Controlled-trial.com: ISRCTN54685764

20

21 Correspondence to:

22 Prof.Dr. H.J. Simonsz, Dept. of Ophthalmology, Room Ee 1607

23 ErasmusMC University Medical Center Rotterdam, P.O. Box 2040, 3000 CA Rotterdam,

24 the Netherlands; simonsz@compuserve.com

27 Word count: 2541

28 Figures: 2; Tables: 2

29 Keywords: amblyopia, occlusion therapy, compliance, electronic monitoring, Protection Motivation Theory 


\section{Abstract}

32 Aim: To analyze psychological causes for low compliance with occlusion therapy for amblyopia.

33 Method: In a randomized trial, the effect of an educational programme on electronically

34 measured compliance had been assessed. 149 families who participated in this trial completed a

35 questionnaire based on the Protection Motivation Theory after 8 months of treatment. Families

36 with compliance less than $20 \%$ of prescribed occlusion hours were interviewed to better

37 understand their cause for noncompliance.

38 Results: Poor compliance was most strongly associated with a high degree of distress $(\mathrm{p}<0.001)$,

39 followed by low perception of vulnerability $(\mathrm{p}=0.014)$, increased stigma $(\mathrm{p}=0.017)$ and logistical

40 problems with treatment $(\mathrm{p}=0.044)$. Of 44 families with electronically measured compliance less

41 than $20 \%, 28$ could be interviewed. The interviews confirmed that lack of knowledge, distress

42 and logistical problems resulted in noncompliance.

43 Conclusion: Poor parental knowledge, distress and difficulties implementing treatment seemed to

44 be associated with noncompliance. For the same domains, the scores were more favourable for

45 families who had received the educational programme than for those who had not. 


\section{Introduction}

48 Amblyopia (lazy eye) is the most frequent cause of visual deficit in childhood and is usually

49 treated with occlusion of the fellow eye, preferably before the age of six years. The degree of

50 compliance is the factor most frequently suggested to influence treatment outcome.[1-4] The

51 development of the Occlusion Dose Monitor (ODM)[4-10] enabled objective monitoring of

52 compliance with occlusion therapy. It was found that compliance averaged $50-60 \% .[3,11]$

53 Since studies have shown that occlusion treatment is effective, $[2,3,10]$ efforts are underway to

54 identify determinants of poor compliance, as well as ways to improve compliance.[9,11,12] The

55 emotional impact[12-14] and poor parental understanding[11] seem to be important factors

56 affecting the implementation of therapy. In a randomized clinical trial we showed that an

57 educational programme, consisting of a cartoon story explaining to the child, without text, the

58 rationale for treatment, together with a calendar and reward stickers, and an information sheet for

59 parents, was effective in improving compliance and reducing the number of children who

60 received no patching.[9] As part of the same trial, this study focuses on the association of

61 psychological factors with compliance. For this purpose a questionnaire was developed, which

62 was adapted from a Protection Motivation Theory (PMT) based questionnaire, [15,16] created

63 and validated by Searle et al. and Norman et al.[17-19] In short, PMT is based on two behavioural

64 adaptations (appraisal of threat and coping appraisal) that occur when an individual faces a health

65 threat. It has been applied to predict a range of health protective behaviour (e.g. threat of HIV

66 infection).[21,21] We used the PMT questionnaire and added questions using the most frequently

67 expressed complaints from both practicing orthoptists and parents of children receiving occlusion

68 therapy. Compliance was measured electronically using the ODM. In addition, reasons for total

69 non-compliance were investigated.

70

71 Methods 
72 The study population was a subset of the large prospective randomized clinical trial $(n=310)$,

73 reported previously.[9] In short, all newly diagnosed amblyopic children treated with occlusion

74 therapy were registered. In addition to standard orthoptic care, included children were

75 randomized: the intervention group received the educational programme, and the reference group

76 did not. Compliance was measured electronically with the ODM, one week, every three months.

77 The ODM was attached to the outside of the patch using double sided adhesive tape. It records

78 the temperature difference between the front and backside every two minutes. The ODM and

79 educational programme were distributed during home visits. During the third one-week ODM

80 measurement, after approximately eight months of therapy, the questionnaire was distributed. The

81 study design was prospective, so children recruited at a later stage in the study did not reach the

82 third ODM measurement and consequently did not receive the questionnaire (figure 1). The

83 Ethical Committee of Erasmus University Rotterdam and the boards of the participating clinics

84 approved the protocol and informed consent forms. Written informed consent by the parents or

85 guardian was a prerequisite for participation. The research adhered to the tenets of the

86 Declaration of Helsinki.

88 Patching Success Questionnaire

89 The questionnaire consisted of ten domains ('Patching Success Questionnaire' -

90 PSQ).[Supplemental File] Eight domains were based on components of the PMT.[17-19] All the

91 PMT items were measured on a 5-point response scale (strongly disagree/strongly agree), scale

92 range from 1 to 5 . Measures of the variables were constructed by averaging responses to

93 individual items such that high scores indicated high degrees on the variable of interest. The PMT

94 contained the following domains: Protection Motivation, (3 items, e.g. 'I expect to patch my child

95 as recommended'); perceived severity of the disease (6 items; e.g. 'I am concerned about my

96 child's visual impairment'); perceived vulnerability (6 items; e.g. 'If left untreated, what are the

97 chances that your child's visual impairment will restrict his/her future choice of occupation'); 
98 response efficacy (5 items; e.g. 'My child's vision will improve in the future if patched

99 regularly'); self-efficacy (4 items; e.g. 'I feel confident in my ability to patch'); perceived distress

100 (8 items; e.g. 'Patching causes distress for my child'); the extent to which patching may interfere

101 or prohibit the child from engaging in every day activities (5 items; e.g. 'Wearing a patch

102 prohibits my child from reading'); and the stigma attached to wearing a patch was assessed using

103 five items (e.g. 'Negative comments from others about the patch upset me').

104 Two domains were added and elaborated on in the study group. Firstly, an inventory was

105 made of the most frequently expressed complaints from the parents, children and practicing

106 orthoptist, which had not been addressed in the questionnaire by Norman et al.[19] Complaints

107 included: not being able to implement the patching treatment into their daily routine: they were

108 unaware as to where to buy the patches; they were unaware of the duration of treatment, etc.

109 Afterwards, during discussions in the study group, these complaints were categorized into two

110 domains: knowledge of disease and knowledge of treatment. A pre-test group $(n=11)$ was asked

111 to complete the questionnaire and comment on the relevance of the questions and whether they

112 understood the questions. Parental knowledge of amblyopia was assessed using 3 items scored on

113 a 5-point scale (response scale: strongly disagree/strongly agree)). Parental knowledge of

114 treatment was assessed using 1 item scored on a 4-point scale. For the analysis, these values were

115 rescaled to an equal range of a 5-point scale (i.e. ' 1 ' equals ' 1 ', '2' equals '2.33'; ' 3 ' equals

116 '3.67'; and '4' equals '5'); again, a high score indicated a high degree on the variable of interest.

117 In addition to these two domains, nine general questions regarding the child's health and logistics

118 of treatment (e.g. 'I find it difficult fitting patching into my daily routine') were asked.

119 The PSQ was completed by the parents and collected one week later. If the parents had difficulty

120 completing the questionnaire, they were assisted by a researcher.

\section{In-depth analysis of the noncompliers by semi-structured interview}


123 Development of the semi-structured interview. In the overall study population $(n=310)$ it was

124 found that $14 \%$ had not been occluded.[9] Therefore, a more in-depth analysis was performed to

125 explore families' experience with occlusion therapy and the causes for noncompliance.

126 First, the group of noncompliers was defined using data from the first one-week ODM

127 measurement. Mean compliance had a bi-modal distribution: the first peak was caused by

128 children who were not occluded, and the second peak represented children who occluded

129 approximately $80 \%$ of the hours prescribed (figure 2). The lowest point was found at the $20 \%$

130 compliance level, which separated the children who had not been occluded or had been occluded

131 infrequently, from the children who occluded regularly. This was consequently chosen as the cut-

132 off point: $44(14 \%)$ children occluded less than $20 \%$ of the prescribed occlusion hours. Second,

133 the noncompliant and more compliant groups were compared concerning the demographic factors

134 and the PSQ scores. The following significant differences, in favour of the compliant group, were

135 found: logistics of treatment $(\mathrm{F}=15.1 ; \mathrm{p}=0.001)$, perceived distress $(\mathrm{F}=12.5 ; \mathrm{p}=0.001)$, Protection

136 Motivation $(\mathrm{F}=12.1 ; \mathrm{p}=.001)$, parental knowledge $(\mathrm{F}=8.13 ; \mathrm{p}=.005)$, self-efficacy $(\mathrm{F}=9.32$;

$137 \mathrm{p}=0.003)$, working knowledge of the Dutch language $(\mathrm{F}=6.64 ; \mathrm{p}=0.01)$ and country of origin

$138(\mathrm{~F}=3.85 ; \mathrm{p}=0.047)$. These differences were used to develop a semi-structured interview with 33

139 questions, including 6 questions specifically for the child. The interview was open framed

140 allowing a focused, conversational, two-way communication. Since compliance was related to

141 fluency in the national language,[9] questions regarding communication and relationship with the

142 treating orthoptist were also included.

143 Application of the semi-structured interview. Parents were interviewed by two researchers (LC

144 and $\mathrm{SdV}$ ) at their home, to overcome the problem of dropouts who no longer visited the clinic.

145 An interpreter was present if the family did not speak Dutch.

146

\section{Statistical analysis}


148 The means, standard deviations, inter-correlations and Cronbach's alpha values of each of the

149 domains were calculated. Cronbach's alpha values higher than 0.60 were considered sufficient for

150 the purpose of group comparison. Test for Normality was performed to determine the distribution

151 of the scores of each domain.

152 Multiple linear regression analysis was used to predict compliance (entered as dependent,

153 continuous variable). The independent variables were: Protection Motivation, severity,

154 vulnerability, response efficacy, distress, prohibition, stigma, self-efficacy, knowledge of disease,

155 knowledge of treatment and logistics of treatment (all entered as continuous variables). F-values

156 and $\beta$-values were calculated. The F-value is a test statistic that tests for differences in the

157 variance between two groups; typically one with and one without a certain predicting variable.

$158 \mathrm{~F}=1$ indicates no difference in variance between the two groups, indicating that no predicting

159 value for the variable could be demonstrated. The percentage of the variation in compliance that

160 could be ascribed to the different factors involved was defined as the ratio of the percentage of

161 the variance explained by the model with, and the model without the factor in question. As

162 potential confounding factors, gender, age, cause of amblyopia, initial visual acuity, fluency in

163 the Dutch language and country of origin were analyzed. Analysis was both univariate and

164 multivariate. Descriptive statistics were applied to analyze the completed semi-structured

165 interviews. $\mathrm{p}<0.05$ was considered statistically significant.

\section{Results}

168 The PSQ was completed for 149 families (99\%). The clinical and demographic characteristics

169 were similar to those reported for the full study cohort $(n=310)$.[9] Mean age of the included

170 children was 4.6 yrs (SD 2.0 yrs); 56\% were boys. Mean acuity in the amblyopic eye (logMAR)

171 at start of therapy was 0.35 (SD 0.32; minimum 1.40; maximum -0.08). 


\section{Patching Success Questionnaire}

174 Mean scores for each domain are shown in table 1. Mean scores for this study were slightly lower

175 than the scores found by Norman et al.,[19] for the domains protection motivation, severity,

176 vulnerability, degree of distress and stigma barrier. The inter-correlations between the domains

177 were comparable to those reported by Norman et al.[19]

178 Univariate analysis of the variance demonstrated that a high degree of distress caused by

179 occlusion therapy was negatively associated with compliance $(\beta=-17 ; \mathrm{p}<0.001$; table 1$)$.

180 Compliance also decreased when the child was prohibited in his or her activities by the patch $(\beta=-$

$1818.4 ; \mathrm{p}=0.01)$. Compliance increased when parents found it easier to implement occlusion therapy

182 into their daily routine $(\beta=11.1 ; \mathrm{p}<0.001)$, when parents were highly motivated to patch their

183 child $(\beta=16.4 ; \mathrm{p}<0.001)$, when parents were able to adhere to the prescription given by the

184 orthoptist $(\beta=12.8 ; \mathrm{p}<0.001)$ and when they thought their child's eye sight would get worse if left

185 untreated $(\beta=10.9 ; \mathrm{p}=0.009)$.

186

187

Table 1.

188 


\begin{tabular}{|c|c|c|c|c|c|}
\hline Domains PSQ & $\begin{array}{l}\text { Alpha } \\
\text { values }\end{array}$ & $\begin{array}{c}\text { Mean scores } \pm \\
\text { SD }\end{array}$ & $\beta$ & $\mathrm{F}$ & P-value \\
\hline 1. Protection Motivation & 0.86 & $4.25 \pm 0.68$ & 16.4 & 14.1 & ${ }^{*}<0.001$ \\
\hline 2. Severity & 0.89 & $3.02 \pm 0.93$ & -3.1 & 0.8 & 0.358 \\
\hline 3. Vulnerability & 0.86 & $3.2 \pm 0.74$ & 10.9 & 6.9 & ${ }^{*} 0.009$ \\
\hline 4. Response efficacy ${ }^{\sim}$ & 0.83 & $4.36 \pm 0.5$ & 5.7 & 0.6 & 0.364 \\
\hline 5. Distress barrier & 0.9 & $2.19 \pm 0.84$ & -17 & 24.2 & ${ }^{*}<0.001$ \\
\hline 6. Prohibit barrier & 0.62 & $2.07 \pm 0.95$ & -8.4 & 6.8 & ${ }^{*} 0.01$ \\
\hline 7. Stigma barrier & 0.78 & $2.48 \pm 0.83$ & -5.9 & 2.5 & 0.116 \\
\hline 8. Self-efficacy ${ }^{\sim}$ & 0.88 & $4.04 \pm 0.86$ & 12.8 & 13.4 & ${ }^{*}<0.001$ \\
\hline 9. Knowledge disease ${ }^{\S}$ & 0.65 & $4.23 \pm 0.65$ & 0 & 0 & 0.998 \\
\hline 10. Knowledge treatment ${ }^{\S}$ & & $4.04 \pm 1.02$ & 2 & 0.4 & 0.546 \\
\hline 11. Logistics of treatment ${ }^{\S}$ & & $2.83 \pm 0.99$ & 11.1 & 13.9 & ${ }^{*}<0.001$ \\
\hline
\end{tabular}


191 capable of implementing the occlusion therapy into their daily routine $(\beta=6.1 ; p=0.044)$ and when

192 they replied that their child's eye sight would get worse if left untreated $(\beta=9.3 ; p=0.014)$.

193 Compliance decreased when distress and stigma increased $(\beta=-22 ; p<0.001$ and $\beta=-6.0 ; p=0.017$,

194 respectively). The four domains explained $22 \%$ of the variation in compliance (adj. $\mathrm{R}^{2}$ ).

\section{In-depth analysis of the noncompliers by semi-structured interview}

197 Of the 44 families, $28(64 \%)$ were interviewed at their home, $11(25 \%)$ could not be contacted

198 due to wrong address or telephone numbers and 5 (11\%) would no longer cooperate.

199 Approximately 30 minutes (range 20-45 min) was spent per home visit. Mean age of the children 200 was 5.7 years (range $4.9-7.2$ years).

201 First, answers were categorized by the three main parties involved in the occlusion

202 therapy i.e. caregiver, child and therapist, allowing for a systematic overview and analysis of the

203 interviews.[22] Second, 12 items were drawn up, 4 for each party involved (table 2). The items

204 refer to reasons for non-compliance as found in our study population. The analysis of the

205 interviews was then conducted a second time by both researchers scoring each report of the

206 interview on the above-mentioned 12 items. This was done on a scale from 1 (not present) to 5

207 (dominantly present or behaviour defining). The two independent scores were analyzed with the

208 weighed kappa-test to test if the two scores differed significantly. 
Table 2.

\begin{tabular}{|lc|}
\hline $\begin{array}{l}\text { Caregiver related } \\
\text { Lack of knowledge of amblyopia }\end{array}$ & $\begin{array}{c}\text { Mean score } \\
\pm \text { SD }\end{array}$ \\
Perceived distress when patched & $3.54 \pm 1.20$ \\
Logistical problems & $2.75 \pm 1.08$ \\
$\quad$ Confidence in effectiveness of therapy & $2.46 \pm 1.26$ \\
Child related & $1.75 \pm 1.24$ \\
$\quad$ Leased by peers & \\
Lower self esteem when patched & $2.29 \pm 1.38$ \\
Poor visual acuity when patched & $2.25 \pm 1.56$ \\
$\quad$ Perceived discomfort when patched & $1.82 \pm 1.10$ \\
Therapist related & $1.96 \pm 1.14$ \\
Addressing problems encounterd during patching & $2.25 \pm 1.38$ \\
Information about disease and treatment & $2.25 \pm 1.32$ \\
Time for questions about disease and treatment & $1.89 \pm 1.28$ \\
Child oriented instructions & $1.75 \pm 1.11$ \\
\hline
\end{tabular}

213 The results of the interview showed that only $14 \%$ of the parents had sufficient

214 knowledge about amblyopia. 57\% reported a high degree of distress and $46 \%$ had difficulties

215 implementing occlusion therapy into their daily routine. Interviewed children replied they were

216 often teased by their peers whilst wearing the patch (43\%, of whom $29 \%$ suffered severe teasing),

217 which decreased their self-esteem. A third of the parents answered they had received incomplete

218 information from the treating orthoptist and that there was little time during the visit to discuss

219 their problems. $18 \%$ of the parents thought that the orthoptist did not sufficiently address the child

220 when explaining the eye condition and its treatment. 


\section{Conclusion \& Discussion}

224 This is the first study to analyze the association between psychological factors and compliance

225 with occlusion therapy in concurrence with the electronic monitoring of compliance. A high

226 degree of distress, a low perception of vulnerability, increased stigma and logistical problems

227 with treatment were associated with poor compliance with prescribed occlusion hours.

228 In concordance with Searle et al.[17,18] and Norman et al.[19] the degrees of response

229 efficacy and protection motivation were high, indicating that most parents thought eye patching to

230 be an effective treatment for their child's amblyopic eye and were motivated to patch their child

231 as prescribed by the orthoptist. This was also found in other studies that applied PMT in relation

232 to compliance with treatment.[18-21,23] For several domains our study population had slightly

233 lower scores than Norman's study population in Bristol. This could be explained by the difference

234 in population, the timing of questionnaire completion and small changes in meaning of translated

235 items.

236 In this study, the questionnaire was given after eight months of treatment. It would have

237 been interesting to have also distributed the questionnaire immediately after the first visit to the

238 orthoptist in order to predict and compare outcomes and assess any changes in opinions during

239 treatment and their influence on compliance. A possible limitation of the study design was that

240 the study ended before all participants had reached the third home visit during which the

241 questionnaire was given. However, baseline characteristics were comparable between the group

242 who had received and completed the questionnaire and the group who had not received it.

243 Compliance, as measured with the ODM, decreased most drastically when parents

244 reported a high degree of distress. This was also found in other studies.[12-14,18,19]

245 Our study population was a subset of the large prospective randomized clinical trial

246 studying whether compliance could be improved using an educational programme.[9] Even

247 though this study was not designed to determine the effect of the programme on the scores of the 
248 questionnaire domains, it would be interesting to observe any effect of the educational

249 programme (using the Mann-Whitney test). This showed that the programme had a positive effect

250 on the level of distress, the ability to implement treatment into the daily routine and parental

251 knowledge about the treatment.

252 When further analyzing the group who did not occlude, it became apparent that only $14 \%$

253 of the parents had sufficient knowledge of amblyopia. Many parents were unaware of their lack

254 of knowledge, and therefore, were less likely to pose questions to the orthoptist. A number of

255 parents indicated that they would prefer the orthoptic visits to be more child-focused. Currently,

256 children are poorly involved in the communication between parent and orthoptist and may

257 therefore not be fully aware of the reason for patching.

258 These findings emphasize that occlusion therapy for amblyopia is difficult to implement,

259 is accompanied by a high degree of distress and is hampered by poor knowledge and

260 understanding. As the more confrontational and argumentative approach towards non-compliance

261 is unsuccessful, a more empathic and supportive style that is less prone to moral judgment, should

262 be used.[24] Various behavioural models (e.g. health belief model), which include both the

263 physician and the patient, have been developed for the purpose of optimal clinical outcome. A

264 useful technique for orthoptists and pediatric ophthalmologists could be the "Shared Decision

265 Making".[25] This is a process by which patient and health care provider consider the outcome

266 probabilities (e.g. equal visual acuity after 6 months of occluding 4 hrs/day) and the patient

267 preference (e.g. both full-time working parents who can accomplish $1 \mathrm{hr} /$ day) and reach a health

268 care decision based on a mutual agreement (e.g. 2 hrs/day, but treatment will continue for

269 approximately one year). The current trend among orthoptists and ophthalmologists is that in

270 individual cases where compliance is faltering, prescribing less hours of occlusion may result in

271 better compliance.

272 Orthoptist's and clinician's knowledge regarding the obstacles which families encounter

273 when they implement occlusion therapy should be improved. This would enhance the orthoptist's 
274 and clinician's confidence in their ability to address the issues and would ultimately improve

275 clinical outcomes. In addition, the educational programme would help clinicians, orthoptists and

276 parents to explain the reason for occlusion therapy to the child and offer guidelines to the parent

277 for carrying out the treatment. 


\section{Acknowledgments}

279 The authors thank Bregje van Dijk, Ellen van Minderhout, Marleen Vermeulen, Roberta Delle

280 Site, Janine van Zon, Eline Deelstra, Jorrien Bouma, Maurits Joosse, Hans Büller, Larisa Pepler,

281 Yaroslava Chopovska, Iris Bachert, Angelika Cordey, Regine Neukam, Heike Bartz, Birgit

282 Herrmann, Marlies Murtro, Dr. Marc Lüchtenberg, Prof. Alina Zubcov and Dr. Claudia Kuhli for

283 their advice, help with data collection and efforts in recruiting the children.

284 The Occlusion Dose Monitor was developed at the department for Medical Technical

285 Development at the Academical Medical Center, Amsterdam, the Netherlands in 1996-1997 as a

286 public domain project.

288 This research was supported by: Health Research and Development Council of the

289 Netherlands; M. Fronius: Albert von Metzler Foundation, Augenstern Association, Research

290 Award of the German Society of Ophthalmology (DOG), Germany.

291 Financial Disclosure: None

292 Authors' contributions: Dr. Loudon and Prof.dr. Simonsz had full access to all the data in the

293 study and take responsibility for the integrity of the data and the accuracy of the data analysis.

294 The independent statistician was Ir. C W N Looman, Department of Public Health and

295 Biostatistics, ErasmusMC University Medical Center Rotterdam, the Netherlands.

296 Licence for Publication: The Corresponding Author has the right to grant on behalf of all

297 authors and does grant on behalf of all authors, an exclusive licence (or non exclusive for

298 government employees) on a worldwide basis to the BMJ Publishing Group Ltd to permit this

299 article (if accepted) to be published in BJO and any other BMJPGL products and sublicences such

300 use and exploit all subsidiary rights, as set out in our licence

301 (http://bjo.bmj.com/ifora/licence.pdf).

302 Competing interests: None declared. 


\section{References}

304 1. Simons K, Preslan M. Natural history of amblyopia untreated owing to lack of compliance. $B r J$ $305 \quad$ Ophthalmol. 1999;83:582-87.

306 2. Dorey SE, Adams GGW, Lee JP, Sloper JJ. Intensive occlusion therapy for amblyopia. $B r J$

$307 \quad$ Ophthalmol. 2001;85:310-3.

308 3. Stewart CE, Fielder AR, Stephens DA, Moseley MJ. Treatment of unilateral amblyopia: factors

309 influencing visual outcome. Invest Ophthalmol Vis Sci. 2005;46:3152-60.

310 4. Loudon SE, Polling JR, Simonsz HJ. Electronically measured compliance with occlusion therapy for

311 amblyopia is related to visual acuity increase. Graefes Arch Clin Exp Ophthalmol. 2003;241:176-80.

312 5. Fielder AR, Irwin M, Auld R, Cocker KD, Jones HS, Moseley MJ. Compliance monitoring in 313 amblyopia therapy. The Lancet. 1994;343:547.

314 6. Simonsz HJ, Polling JR, Voorn R, et al. Electronic monitoring of treatment compliance in patching for 315 amblyopia. Strabismus. 1999;7:123-33.

316 7. Chopovska Y, Loudon SE, Cirina L, et al. Electronic recording of occlusion treatment for amblyopia:

317 potential of the new technology. Graefes Arch Clin Exp Ophthalmol. 2005;243:539-44.

318 8. Fronius M, Chopovska Y, Nolden J, et al. Occlusion treatment for amblyopia: assessing the 319 performance of the electronic occlusion dose monitor. Strabismus. 2006;14:65-70.

320 9. Loudon SE, Fronius M, Looman CWN, Awan M, Simonsz B, van der Maas PJ, Simonsz HJ.

321 Predictors and a remedy for non-compliance with amblyopia therapy in children measured with the 322 Occlusion Dose Monitor. Invest Ophthalmol Vis Sci. 2006;47:4393-400.

323 10. Stewart CE, Stephens DA, Fielder AR, Moseley MJ; for the ROTAS Cooperative. Objectively 324 monitored patching regimens for treatment of amblyopia: randomised trial. BMJ 2007;335:707-13.

325 11. Newsham D. A randomised controlled trial of written information: the effect on parental non-

326 concordance with occlusion therapy. Br J Ophthalmol 2002;86:0-4.

327 12. Dixon-Woods M, Awan M, Gottlob I. Why is compliance with occlusion therapy for amblyopia so 328 hard? A qualitative study. Arch Dis Child 2006;91:491-4.

329 13. Hrisos S, Clarke MP, Wright CM. The emotional impact of amblyopia treatment in preschool children. $330 \quad$ Ophthalmol. 2004;111:1550-6. 
331 14. The Pediatric Eye Disease Investigator Group. Impact of patching and atropine treatment on the 332 child and family in the Amblyopia Treatment Study. Arch Ophthalmol. 2003;121:1625-32.

333 15. Rogers RW. A protection motivation theory of fear appeals and attitude change. $J$ of Psychology $334 \quad 1975 ; 91: 93-114$.

335 16. Rogers RW. Cognitive and psychological processes in fear appeals and attitude change: A revised

336 theory of protection motivation. In B.L. Cacioppo, L.L. Petty \& D. Shapiro (Eds), Social

337 Psychophysiology: A Sourcebook. London: Guilford Press.

338 17. Searle A, Vedhara K, Norman P, Frost A, Harrad RA. Compliance with eye patching in children and

339 its psychosocial effects: A quantitative application of protection motivation theory. Psychology, Health $340 \quad$ and Medicine 2000;43-54

341 18. Searle A, Norman P, Harrad RA, Vedhara K. Psychosocial and clinical determinants of compliance 342 with occlusion therapy for amblyopic children. Eye. 2002;16:155-5.

343 19. Norman P, Searle A, Harrad RA, Vedhara K. Predicting adherence to eye patching in children with 344 amblyopia: An application of protection motivation theory. Br J Health Psychology. 2003;8:67-82.

345 20. Abraham CS, Sheeran P, Abrams D, Spears R. Exploring teenagers adaptive and maladaptive 346 thinking in relation to the threat of HIV infection. Psychology and Health. 1994;9:253-72.

347 21. Rippertoe PA, Rogers RW. Effects of components of protection motivation theory on adaptive and 348 maladaptive coping with a health threat. J of Personality and Social Psychology. 1987;52:596-604.

349 22. DiMatteo RM. Review. The role of effective communication with children and their families in 350 fostering adherence to pediatric regimens. Patient Educ Couns 2004;55:339-44.

351 23. Rudman LA, Gonzales MH, Borgida E. Mishandling the gift of life: Non-compliance in renal 352 transplant patients. J of Soc and Appl Psychol. 1999;29:834-51.

353 24. Sutten S. Health Behavior: Psychosocial Theories. International Encyclopedia of the Social \& 354 Behavioral Sciences. 2001:6499-506.

355 25. Frosch DL, Kaplan RM. Shared Decision Making in Clinical Medicine: Past research and future 356 directions. Am J Prev Med 1999;17:285-94. 


\section{Legends}

360 Figure 1. Flowchart illustrating the study design. After the first one-week measurement, children

361 who patched less than $20 \%$ of the prescribed occlusion time were identified as noncompliant.

362 Between November 2004 and March 2005, the noncompliant group received a separate semi-

363 structured interview with more in-depth questions that was based on differences in answers from

364 the Patching Success Questionnaire between the more compliant and the noncompliant group.

366 Figure 2. Bar chart presents compliance with prescribed occlusion hours during the first one-

367 week ODM measurement, with $10 \%$ intervals.

369 Table 1. Cronbach's alpha, overall mean scores on a 5-point scale $( \pm \mathrm{SD})$ per domain, scale from

3701 to 5 with a higher score indicating a high level of interest

$371 \sim$ The PMT items of the Patching Success Questionnaire;

$372 \S$ Added items by our study group;

$373 \dagger$ The association between compliance and mean scores; *P-value indicates a significant

374 influence of the domain on compliance using linear regression analysis;

376 Table 2. Mean scores $( \pm \mathrm{SD})$ for the 12 items derived from the semi-structured interview, which

377 refer to reasons for total noncompliance. They are subdived into the caregiver, the child and the 378 therapist. 


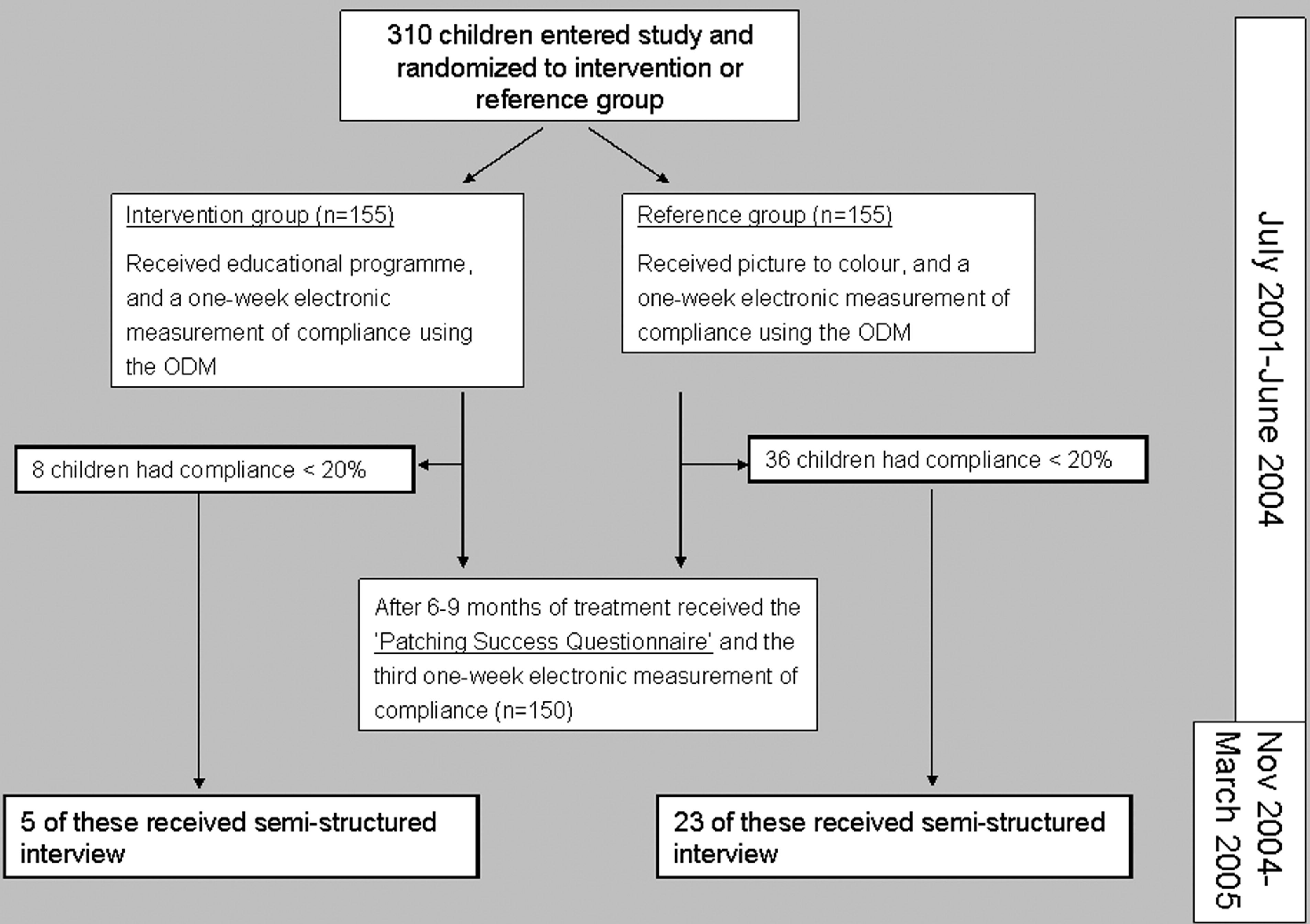




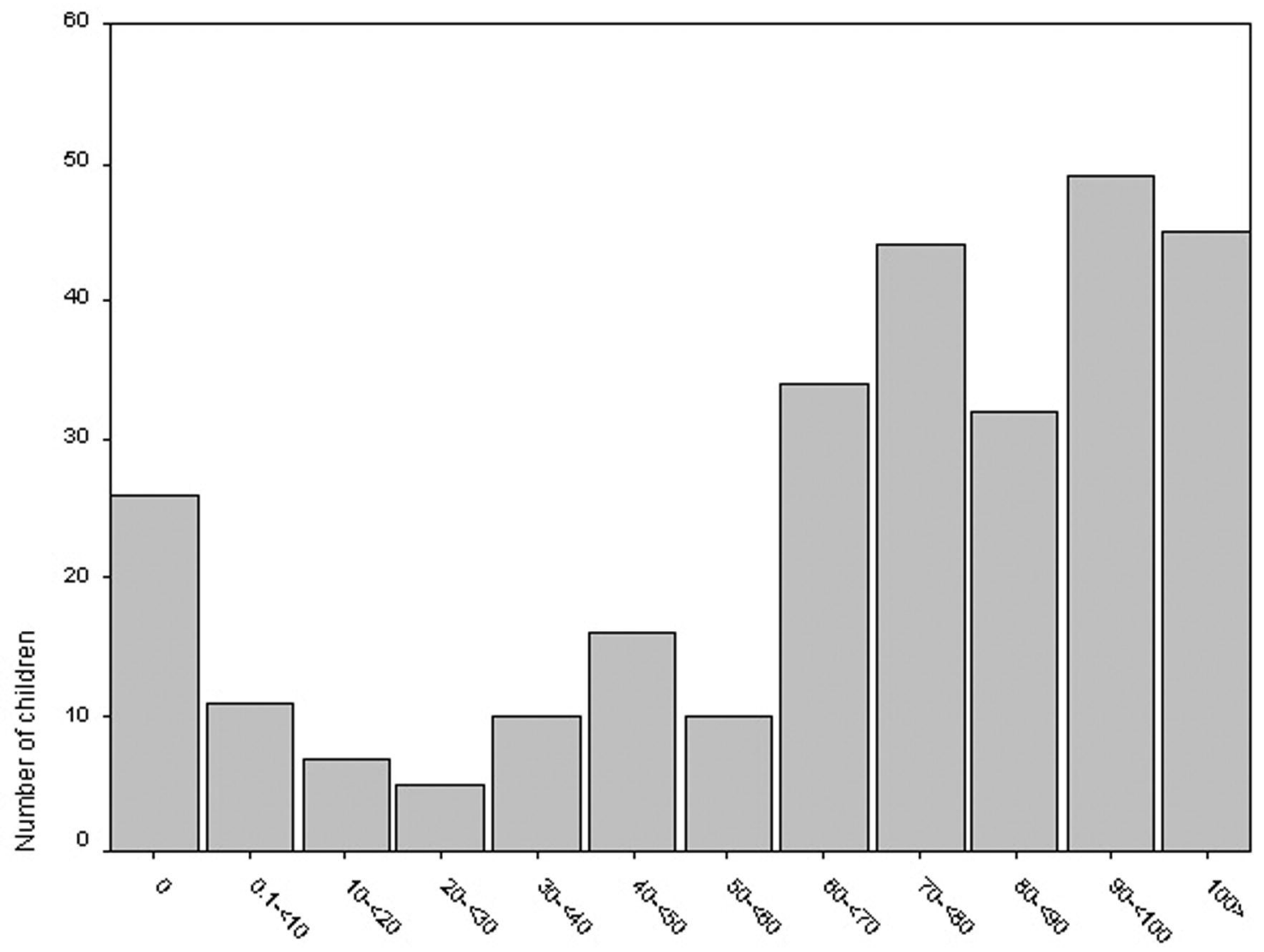

Compliance (\%) 0-3 mos after start of therapy 